\title{
Kretzschmaria deusta, a limiting factor for survival and safety of veteran beech trees in Trentino (Alps, Northern Italy)
}

\author{
Giorgio Cordin (1), \\ Giorgio Messina ${ }^{(2)}$, \\ Giorgio Maresi ${ }^{(1)}$, \\ Fabio Zottele ${ }^{(1)}$, \\ Fabrizio Ferretti ${ }^{(3)}$, \\ Lucio Montecchio ${ }^{(4)}$, \\ Claudia Maria Oliveira Longa ${ }^{(5)}$
}

\begin{abstract}
The importance of veteran trees is well recognised nowadays. The sudden breakage of some of these plants in Trentino (Italy), mainly due to Kretzschmaria deusta, prompted a survey of the veteran beeches reported in this area. Visual tree assessment was carried out in 40 sites with either single trees or groups of beeches, for a total of 115 trees evaluated. Most trees showed serious defects or problems in need of management and 19 had a high level of risk of breakage because of the presence of several structural problems. The presence of $K$. deusta was recorded on $50.4 \%$ of the examined trees. The pathogen was also identified in the proximity of investigated trees at 29 sites. Laboratory tests confirmed the identity of $K$. deusta by microbiological and molecular approaches and also identified Cosmopora berkeleyana as mycoparasite on $K$. deusta fruiting bodies. Isolates obtained from declining trees and old stumps showed the same pattern of growth at different temperatures. The risk evaluation emphasised how the fungus could affect the survival and safety of these veteran trees; this was confirmed by the collapse of four of the investigated trees in the last years. Therefore, $K$. deusta, which has been considered as a facultative parasite up to now, could play a more incisive role both in the decline of old beech trees and the natural evolution of aging beech woods.
\end{abstract}

Keywords: Fagus sylvatica, Xilariaceae, Brittle Cinder, Soft-rot, Visual Tree Assessment, Veteran Tree Conservation

\section{Introduction}

In the last years an increased comprehen sion of the role of veteran trees has en

$\square$ (1) Fondazione Edmund Mach, Technology Transfer Centre, v. E. Mach 1, 38010 San Michele all'Adige, TN (Italy); (2) Forest Service, Autonomous Province of Trento - PAT, v. G.B. Trener, 3 - 38121 Trento (Italy); (3) CREA Research Centre for Forestry and Wood, v.le Santa Margherita 80, 52100 Arezzo (Italy); (4) University of Padova, Department of Land, Environment, Agriculture and Forestry, v.le dell'Università 16, 35020 Legnaro, PD (Italy); (5) Fondazione Edmund Mach, Research and Innovation Centre, Department of Sustainable Agroecosystems and Bioresources, San Michele all'Adige, TN (Italy)

\section{@ Giorgio Maresi (giorgio.maresi@fmach.it)}

Received: Mar 27, 2021 - Accepted: Oct 29, 2021

Citation: Cordin G, Messina G, Maresi G, Zottele F, Ferretti F, Montecchio L, Oliveira Longa CM (2021). Kretzschmaria deusta, a limiting factor for survival and safety of veteran beech trees in Trentino (Alps, Northern Italy). iForest 14: 576-581. - doi: 10.3832/ifor3830-014 [online 2021-12-18]

Communicated by: Alberto Santini hanced not only their aesthetic, historical and monumental value, but also their ecological role as biodiversity reservoirs (Zapponi et al. 2017). Attention to these veteran, ancient or large old trees (Read 2000, Hall \& Bunce 2011, Lindenmayer et al. 2012) is anyway not new, as their value is well understood by many local communities, where old trees grow and contribute to identity (heritage trees) for historical and cultural reasons (Orlowski \& Nowak 2007). According to Lonsdale (2013), "some of them have become so familiar to certain communities that they have become like well-loved friends". Veteran trees with their individual aesthetic qualities are generally also focal points in the landscape, providing high amenity value and also visual enjoyment as well as an enrichment both in fauna and flora variety. The concept of "functional uniqueness" fits these ancient trees very well because of the unusual effect that they can have on both ecosystems and landscapes (Manning et al. 2006 - Fig. S1 in Supplementary material).

In this context, conservation of these valuable trees is becoming a primary goal in urban and landscape management. Their high value was recognized in Italy by a specific law in 2013 (Law n.10 14/01/2013) and by the subsequent Ministerial Decree (DM 23/10/2014). These legislative acts for the first time define the concept of veteran trees suggesting clear criteria for their identification; the law requires that munici- palities inventory the veteran trees in their territory, also recovering previous local actions of mapping and protection. Recently, guidelines (Farina et al. 2019) have been proposed to suggest a correct management of these trees, also considering mortality risk and phytosanitary problems.

In this context, the sudden breakdown of some veteran trees reported in the last years in Trentino (Northeastern Italy) raised concerns about the health status of the recorded veteran trees. Particularly, the constant presence (100\%) of Kretzschmaria deusta (Hoffm.; Fr.) P.M.D. Martin on the more recently fallen trees suggested a possible direct role of this pathogen in the decaying process. It is to remember that the decay caused by $K$. deusta is particular because the fungus degrades cellulose creating holes in cell secondary walls. This degradation reduces the tensile strength of wood that becomes brittle and easy to snap off with a characteristic fracture (Luley 2017). Moreover, the presence of dark lines due to the fungus in the decayed wood is considered a typical characteristic of K. deusta (Wilkins 1934)

To investigate this subject, a complete survey of veteran beech (Fagus sylvatica L.) trees, among the most endangered in recent years, was carried out. The main goal of this study was to estimate whether and how much the presence of $K$. deusta could be related to the damages and to the failure risk conditions of the surveyed trees. 
Moreover, the effect of some environmental and meteorological conditions on pathogen behaviour have been also considered in order to enhance the management practices.

\section{Materials and methods}

\section{Field investigations}

\section{Veteran beeches in Trentino}

In 2015, the Forest and Fauna Service of the Autonomous Province of Trento carried out a complete revision of the veteran trees defined as "monumental", aiming to harmonize the previous inventory of 2003 with the more recent criteria proposed by the national law. Dead and fallen trees as well as the smallest ones were removed from the record. The criteria followed were: 1. age and size (with species-specific trunk circumference thresholds, for beech $400 \mathrm{~cm}) ; 2$. peculiar shape; 3. ecological value; 4. botanic rarity; 5 . plant architecture; 6 . landscape value; 7 . historic-culturalreligious aspects.

In each administrative forest district, surveys were carried out aimed to identify the most representative single trees or groups that were mapped and geo-localized. Of these, 115 beech trees were selected for this specific investigation.

\section{Visual Tree Assessment (VTA) of identified} veteran trees

The selected trees were examined during field surveys carried out in March and April 2016.

According to Pezzi et al. (2020), diameter at breast height (DBH) and tree height were measured on each selected tree. Vitality, presence of pathogens and pest, structural condition and failure risk were then evaluated. Vitality was expert-based assessed on crown condition (transparency or death of branches), adopting the following scale modified from Müller \& Stierlin (1990): (i) vigorous tree, crown completed; (ii) slightly suffering, defoliation or death of branches up to $20 \%$ of the whole crown; (iii) suffering, defoliation or death of branches from $20 \%$ to $50 \%$ of the whole crown; (iv) declining defoliation or death of branches from $50 \%$ to $75 \%$ of the whole crown; ( $v$ ) dead, defoliation or death of branches over $75 \%$ of the whole crown. Moreover, the presence of other fungal attacks on the collars or stems was assayed.

The conditions of the trees was evaluated considering the presence of damage and structural anomalies in the different tree parts; (i) crown: asymmetry, death of branches, signs of pruning, other wounds, decaying wood with rot and/or cavities on branches, fungal fruiting bodies; (ii) trunk: leaning, wounds, decaying wood with rot and/or cavities (\% of diameter), fungal fruiting bodies; (iii) collar and root: wounds with decaying wood, rot and/or cavities (\% of diameter), fruiting bodies, excavation or soil movement in the root area, soil cracking.

Site conditions (wind exposure and natural or altered soil condition) and surrounding type of environment (wood, pastures, or urban area) were recorded. Target rating was assessed considering the occurrence of potential targets (structures or human occupancy of the area) under or in proximity to the trees (Matheny \& Clark 1994): absence, occasional or intermittent presence; frequent or constant presence.

The level of damage and related failure risk was assessed by adapting the risk classes reported by Smiley et al. (2017): low risk (no damage); moderate risk (low level of damage, management needed); high risk (medium level of damage, problems

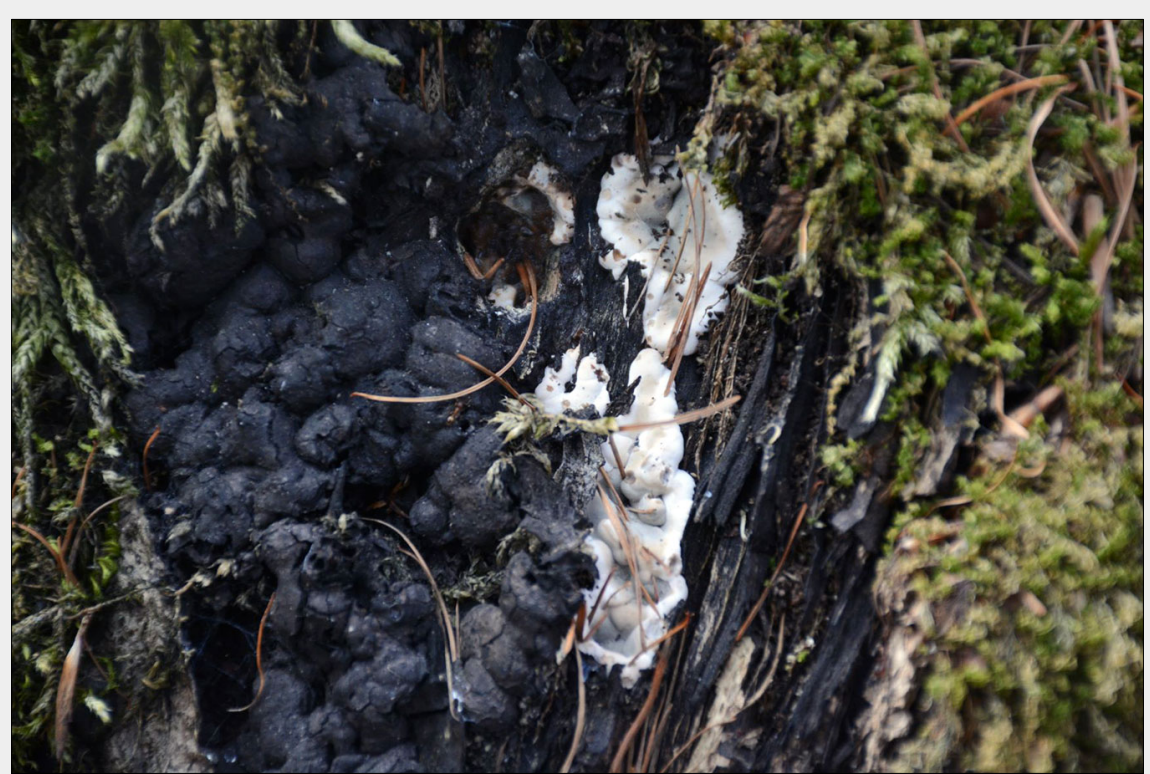

Fig. 1 - Fruiting bodies of Kretzschmaria deusta, sexually reproductive black charcoallike crusts and white/grey asexual stage, on a degraded beech trunk. for tree stability and need for constant management); extreme risk (high level of damage, tree stability strongly affected and few or no possibilities of management).

A specific observation on fruiting bodies belonging to K. deusta (Fig. 1) and related decay attacks was carried out recording their presence and extent on the tree. The occurrence of other fungal fruiting bodies were also recorded.

A buffer area of $50 \mathrm{~m}$ around the examined trees was surveyed aiming to detect the condition of other beech trees or stumps and, particularly, to find the presence of $K$. deusta fruiting bodies and related damage.

\section{Laboratory test}

\section{Morphological characterization}

Parts of trunks of infected trees containing xylariaceous stromata were transferred to the laboratory. Single ascospore cultures were obtained from ascomata based on the method described by Rogers \& Ju (1998). Morphological observation of colonies growing in Malt Extract Agar (MEA) dishes at $25{ }^{\circ} \mathrm{C}$ was carried out with an $S M Z 1000^{\circledast}$ stereomicroscope (Nikon, USA), while microscopic features, such as size, shape, colour and arrangement of conidia, were observed with an Eclipse $80 \mathrm{i}^{\oplus}$ microscope (Nikon) dotted with a digital sight images (DS-L2 imaging controller, Nikon). Light microscope observation of ascospores was done in distilled water and measurements were determined.

\section{Molecular identification}

Genomic DNA was extracted directly from stromata. Each sample was frozen with liquid nitrogen and ground using a sterile mortar and pestle. DNA was extracted using $200 \mathrm{mg}$ of the fine powder obtained from the frozen stromata using a DNeasy ${ }^{\circledR}$ Plant Mini kit (Qiagen, Hilden, Germany) according to the manufacturer's instructions. DNA samples were stored at -20 ${ }^{\circ} \mathrm{C}$. The DNA amplification was obtained by polymerase chain reaction $(P C R)$ using the primers pair ITS5 (5'-GAAAGTAAAAGTCGTAACAAGG-3') and ITS4 (5'-TCCTCCGCTTATTGATATCC-3') to amplify ribosomal ITS1 and ITS2 (White et al. 1990). The PCR mixture comprised $12.5 \mu \mathrm{l}$ of GoTaq $^{\circledast}$ Green Master Mix (Promega), $10.5 \mu \mathrm{l}$ of water supplied with the GoTaq, each primer at 0.2 $\mathrm{mM}$ (Sigma-Aldrich) and $1 \mu \mathrm{l}$ of DNA. A Biometra T1 Thermocycler (Whatman Biometra, Gottingen, Germany) was used for PCR with the following protocol: $5 \mathrm{~min}$ at $95^{\circ} \mathrm{C}$; 35 cycles of denaturation at $95^{\circ} \mathrm{C}$ for $30 \mathrm{~s}$, annealing at $55^{\circ} \mathrm{C}$ for $45 \mathrm{~s}$ and extension at $72{ }^{\circ} \mathrm{C}$ for $1 \mathrm{~min}$; and a final extension step at $72{ }^{\circ} \mathrm{C}$ for $10 \mathrm{~min}$. PCR fragments were analysed using $1 \%$ agarose gel electrophoresis in 1x Tris-boric acid-EDTA buffer (TBE), stained with SYBR Safe ${ }^{\circledR}$ (Life Technologies, Milan, Italy) and visualized under UV light. As a size standard, the GeneRuler ${ }^{\oplus}$ DNA 
ladder mix (Thermo Scientific, USA) was used. Negative (sterile water) and positive controls (a known sample of fungal DNA) were included in all $P C R$ runs.

DNA was sequenced using the ABI PRISM Big Dye Terminator Cycle Sequencing Ready Reaction Kit ${ }^{\circledast}$ v. 3.1 (Applied Biosystems, Warrington, UK) and the PCR primers. Sequencing was performed on an automated DNA sequencer (ABI 3730xl Genetic Analyzer, Applied Biosystems). Sequences derived from this study were deposited at the NCBI GenBank nucleotide database (http://www.ncbi.nlm.nih.gov).

\section{Effect of temperature on mycelial growth}

The influence of temperature on mycelial growth was assessed in vitro. To evaluate the possible difference of behaviour between the strains of the fungus, three isolates of $K$. deusta, one obtained from a decayed stump and two others from living declining trees, were selected for growth assay. Mycelia plugs $5 \mathrm{~mm}$ in diameter were cut from 10-day-old colonies and transferred onto Petri dishes containing Potato Dextrose Agar (PDA, Oxoid, UK). Three replicate dishes were incubated in the dark at $0,5,10,15,20,25,30$ and $35^{\circ} \mathrm{C}$. The rays of the resulting colonies were measured at 1, 3, 7, 10 and 14 days from inoculation. Differences in isolates and replication were compared with ANOVA using STATISTICA $^{\circledast}$ v. 13.3 (StatSoft Inc., Tulsa, OK, USA). Fisher's least significant difference was used to test for significant differences among the means $(\alpha=0.05)$. The experiment was repeated twice and the mean data was presented.

\section{Meteorological data}

Yearly and daily mean temperatures for the period 1983 to 2020 were obtained from the meteorological station at San Michele all'Adige (209 $\mathrm{m}$ a.s.l., FEM agrometeorological network), located in central Trentino. We used freely available meteorological data series of daily average, minimum and maximum temperatures to obtain the yearly and daily average values. The provider does not directly provide climatic (or aggregated) data but guarantee the correctness of the measurements and their elimination in instances of instrument malfunction. Moreover, the provider does not supply information regarding data validation procedures.

\section{Statistical analysis}

The collected data were processed in order to find a relationship between the occurrence of the disease and alternatively the occurrence in the area (dependent variables) and the measurements collected in the field (independent variables). The analysis led to the definition of two different possible models based on the relevant variables for this specific domain knowledge: (i) disease presence $\sim$ area presence + elevation + position + circumference + age; (ii) area presence $\sim$ disease presence + eleva- tion+ circumference +age + rot.

All those variables that were collinear to the combination of the independent variable and the variables already present in the model were excluded.

Once the candidate variables for the model had been identified, the most parsimonious model (lowest complexity, i.e., using the fewest variables) was sought, without compromising the predictive ability. Stepwise model selection based on the Akaike Information Criterion (AIC) was used.

\section{Results}

\section{Field investigations}

\section{Veteran beeches in Trentino}

Overall, 40 sites were considered of interest by the Forest Service for the presence of veteran beech (Tab. S1 in Supplementary material). In 10 sites, the identified trees were single trees on pastures or meadows, probably left as shade for the livestock or near huts or private houses. In 19 sites the surviving giants are old trees in a woodland context either as released standards in coppices or as isolated trees surrounded by new trees or on the edge of younger woodlands.

In six sites the survey selected groups of trees scattered or in rows on pastures. In other three sites the signalled groups were reported as old rows on the edge of a woodland, while the last two sites were located in an urban context. A total of 115 trees were evaluated, 31 as isolated and 84 in the groups. Of all trees, 29 trees formed groups while another 19 were single individuals in a woodland. Fifty-five trees formed groups and 10 trees were single individuals on pastures and the last 2 trees were growing in gardens near houses.

The range of altitude went from 780 to $1630 \mathrm{~m}$ a.s.l. All the trees were growing in a mountain context on slopes or on a plateau.

\section{VTA of identified veteran trees}

At the time of the survey (spring 2016), the evaluation of the failure risk on the basis of all the examined components produced the following result: $39 \%$ low risk; $43 \%$ moderate risk; $16 \%$ high risk and $2 \%$ extreme risk (Tab. S1 in Supplementary material).

Interestingly, one of the trees classified as being at extreme risk was found to have recently failed at the time of the survey because of evident root rot, while the other had a complete breakdown exactly 15 days after the evaluation (Fig. 2). The $43 \%$ of the trees showed significant defects or problems in need of management and $6 \%$ had a high level of risk because of the presence of several structural problems. The $54 \%$ of trees showed damage or presence of rot at collar level, while $30 \%$ had wounds and rot on the trunk. The $11 \%$ of trees had a crown with broken or dead branches. Only $2 \%$ trees had significant damage, mainly wounds, on the roots.

The presence of $K$. deusta was recorded on $50.4 \%$ of the examined trees, mainly as characteristic fruiting bodies or typical wood degradation. The affected trees were present in each of the site conditions: $58 \%$ of the single trees in a woodland, $42 \%$ of the single trees in pastures or gardens, $49 \%$ of trees growing as a group in pastures and $52 \%$ of those living as a group in a woodland. One tree showed only a well-developed typical rot of the trunk, while in all the others the presence of the fungus was clearly identified by the fruiting bodies. In

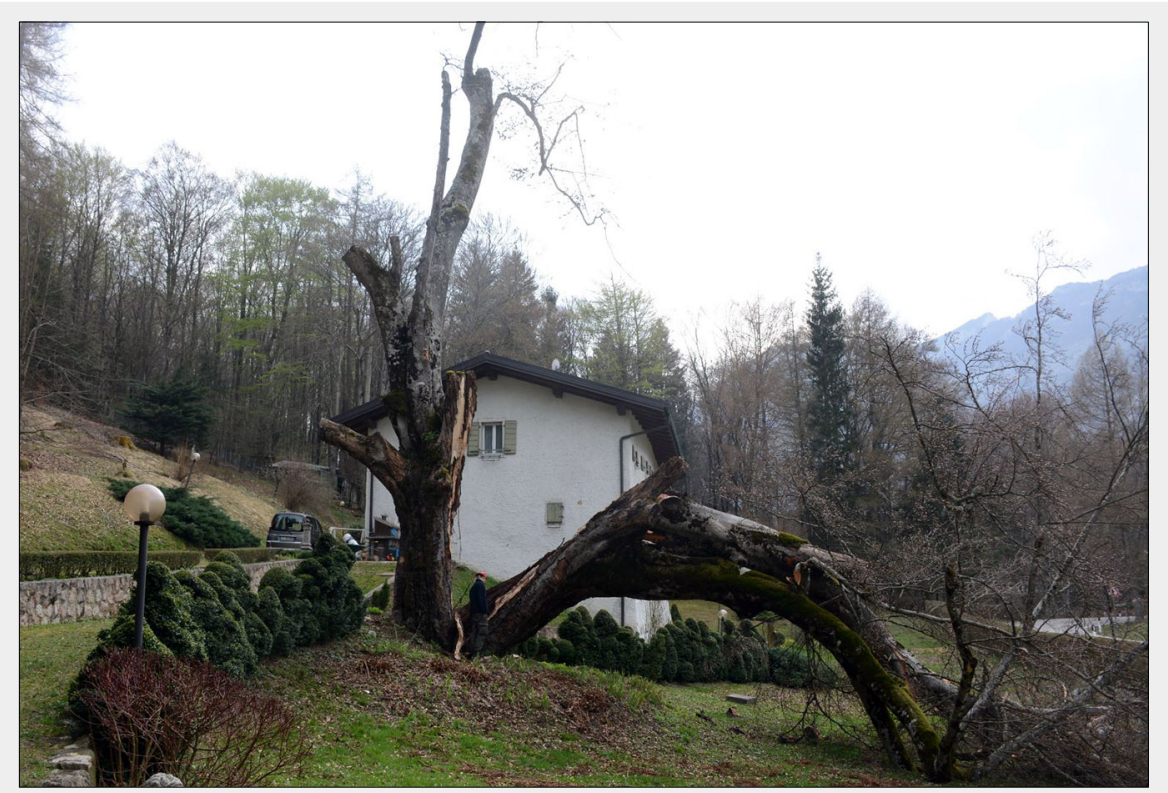

Fig. 2 - Breakdown of the veteran beech tree at the Cà vecia occurred fifteen days after the survey: the tree was considered at extreme risk for the complete colonization by Kretzschmaria deusta. 


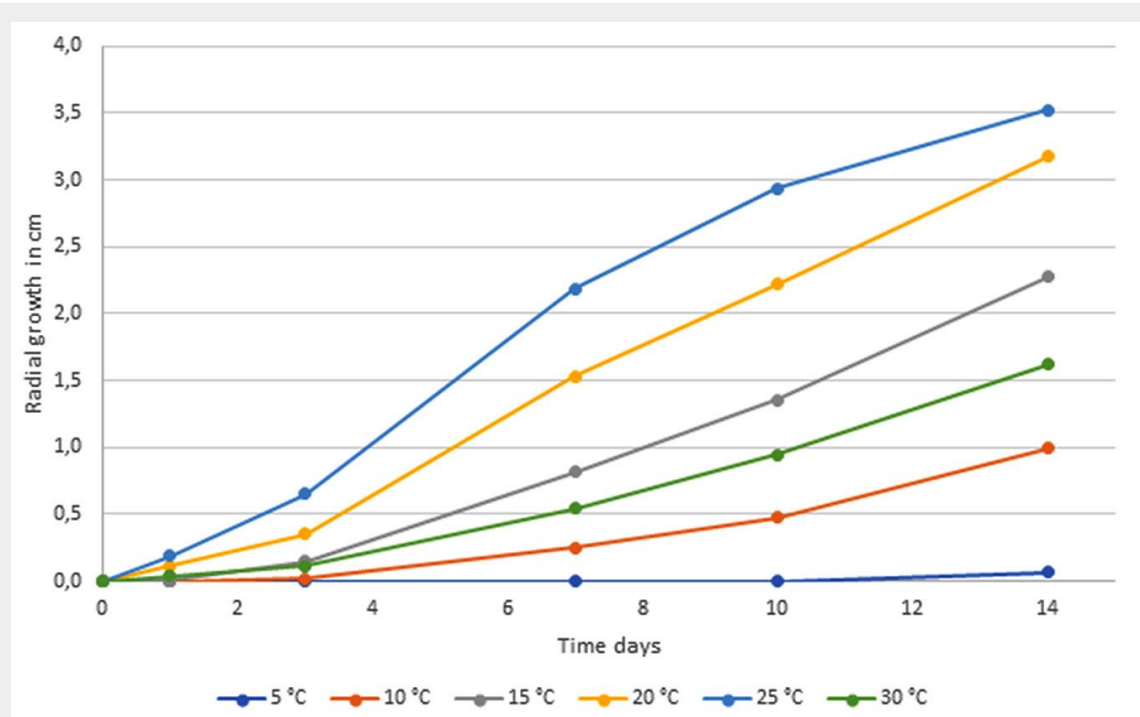

Fig. 3 - Mean values of radial growth (measured on four axes) at different temperatures of three Kretzschmaria deusta isolates. No growth was observed at $0{ }^{\circ} \mathrm{C}$ and 35 ${ }^{\circ} \mathrm{C}$ over the whole observation period (data not shown).

14 trees these were observed on less than $10 \%$ of the collar circumference; in other 29 the colonization involved less than $50 \%$ of the circumference and in the remaining 15 it ranged between $60 \%$ up to $80 \%$. The fruiting bodies or evident rot was limited to the base of the trunk (up to $1 \mathrm{~m}$ ) in 20 trees, while on other 23 the fungus colonized up to $2 \mathrm{~m}$. Fifteen trees showed colonization between 2 up to $6 \mathrm{~m} ; 5$ or $6 \mathrm{~m}$ of infected tissues were detected on 3 of these latter.

On 22 trees other fungi were observed and identified by means of morphological observation. On 12 trees, Armillaria spp. was present both as old fruiting bodies or mycelium, while on the roots of other 5 trees the fruiting bodies of Meripilus gigan teum (Pers.) Karst were evident. Ganoderma resinaceum Boud. was present on other 5 trees, while Schizophyllum commune $\mathrm{Fr}$. colonized part of one of the $K$. deusta affected trees.

K. deusta was detected in 21 areas on living beeches or in the stumps around the surveyed trees. In 8 of these areas the fungus was present only in the surroundings but not on the veteran trees. In 7 areas $K$. deusta was not observed either on the veteran trees or nearby.

\section{Laboratory tests}

\section{Morphological and molecular} identification

Species identification combines sequence information for the internal transcribed spacer (ITS) of rDNA with morphology of stromata sampled at the trunk base of infected trees and microbiological characteristics. Mature stromata appear as black charcoal-like crusts with an irregularly rugose surface dotted with inconspicuous perithecial mounds. The ascospores are fusiform, brown to dark brown, smooth, nonseptate, $24-33 \mu \mathrm{m} \times 6.5-8.5 \mu \mathrm{m}$, on the average $29 \times 7.5 \mu \mathrm{m}$.

Cultures on MEA at $25^{\circ} \mathrm{C}$ reached more than $70 \mathrm{~mm}$ in diameter in 18 days, first whitish, felty and zonate, then becoming grey from the centre outwards with concentric zones. Amplification of the ITS loci yielded fragments of approximately 600 bps. The sequences obtained $100 \%$ of similarity with $K$. deusta using the basic GenBank local alignment search tool program (BLAST). At least one sequence obtained from each site was published in Genbank (accession numbers from MT573939 to MT573952). Moreover, two sequences resulted as having $100 \%$ homology with the mycoparasite Cosmopora berkeleyana (P. Kars.) Gräfenhan, Seifert \& Schroers. (accession number MT626674-75). In fact, the presence of reddish pear shape perithecia was observed on the surface of the fruit bodies of $K$. deusta (Fig. S2 in Supplementary material), suggesting that this fungus is parasitized by other fungi. Indeed, Herrera et al. (2016) demonstrated that most host-parasite links considered coevolutionary included Cosmospora associated with Kretzschmaria, Stilbohypoxylon, and Xylaria hosts.

\section{Effect of temperature on pathogen mycelial growth}

No significant differences ( $p>0.05$ ) were found between the growth of the K. deusta isolates from living declining trees and decayed stumps. As shown in Fig. 3 , the three isolates were able to grow in a range of temperatures varying from 10 to $30^{\circ} \mathrm{C}$, whereas no growth was observed at $0{ }^{\circ} \mathrm{C}$ and $35{ }^{\circ} \mathrm{C}$, while at $5{ }^{\circ} \mathrm{C}$ a reduced initial growth was observed only at the end of the observation period. In general, the rate of mycelial growth increased as temperature increased up to $25{ }^{\circ} \mathrm{C}$ and then decreased rapidly as further increased. At 10 ${ }^{\circ} \mathrm{C}$, mycelial growth of all isolates was slow with an average rate of $0.6 \mathrm{~mm} \mathrm{day}^{-1}$, compared to significantly higher rates of 1.9 , 3.3 and $4.1 \mathrm{~mm}^{\circ} \mathrm{day}^{-1}$, noted at $15{ }^{\circ} \mathrm{C}, 20{ }^{\circ} \mathrm{C}$ and $25{ }^{\circ} \mathrm{C}$, respectively. Optimum growth occurred at $25^{\circ} \mathrm{C}$ for all isolates. A temperature of $35^{\circ} \mathrm{C}$ devitalized the fungus, while at $0{ }^{\circ} \mathrm{C}$ it was able to grow again when exposed to the optimal temperature.

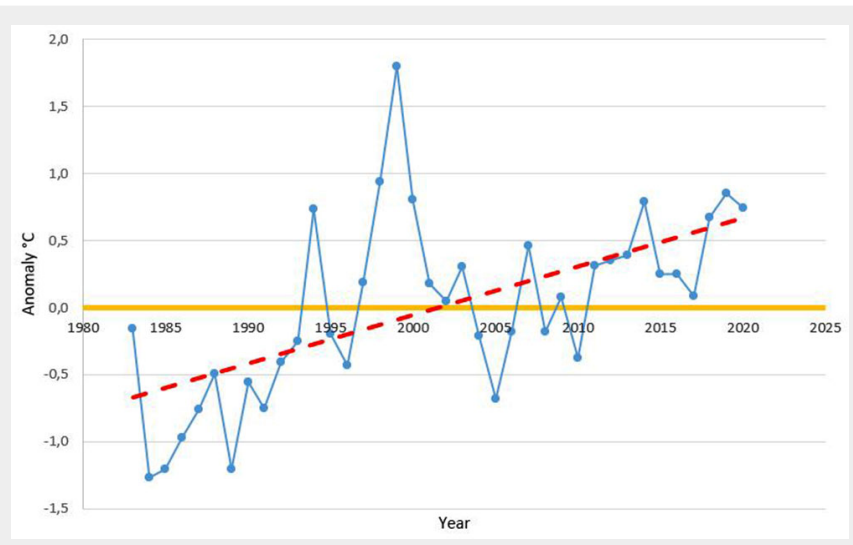

Fig. 4 - Annual mean air temperature anomaly in ${ }^{\circ} \mathrm{C}$ (data source: meteorological station at San Michele all'Adige, Trentino, Italy).

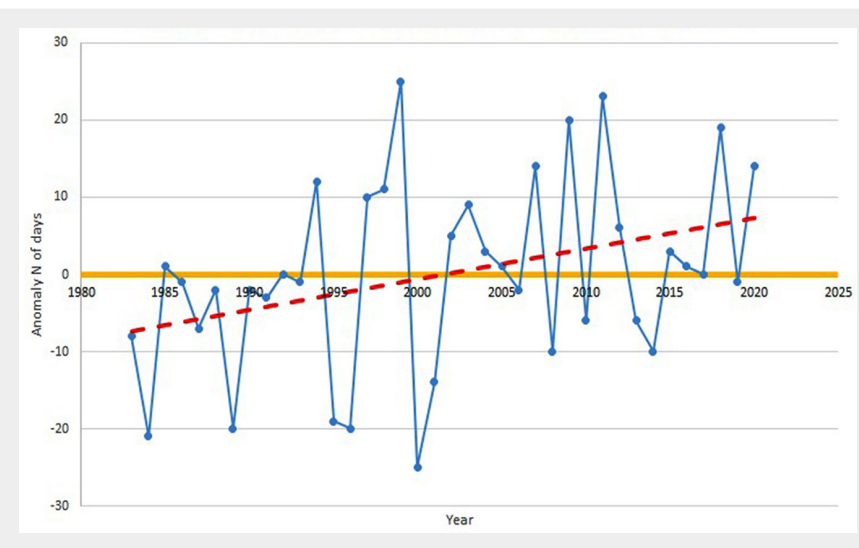

Fig. 5 - Anomaly of mean number of days with average temperature above $18{ }^{\circ} \mathrm{C}$ (data source: meteorological station at San Michele all'Adige, Trentino, Italy). 


\section{Meteorological data}

Data obtained from the meteorological station at S. Michele all'Adige are reported in Fig. 4 and Fig. 5.

The anomalies of mean annual temperature showed a clear slight increase in the considered period, with a rise of almost 0.5 ${ }^{\circ} \mathrm{C}$ in the last years. Moreover, this trend is emphasised by the anomalies in the number of days with mean temperature above $18{ }^{\circ} \mathrm{C}$, which in the last year was 10 to 20 days above the average value.

This is in accordance with what was reported by Tudoroiu et al. (2016), who recognised the same trend of temperature increase in Trentino and the Eastern Alps, despite the mitigating effect of elevation.

\section{Statistical analysis}

The analysis led to the definition of two different possible models based on the relevant variables for this specific domain knowledge but, in both cases, no statistical significance was found between the presence of the disease and the independent variables.

\section{Discussion and conclusion}

The survey clearly demonstrated the abundant presence of $K$. deusta in Trentino and its possible and effective role on the survival of the recorded veteran beeches. The presence and damage due to the pathogen was observed on $50.4 \%$ of the examined trees, in some cases associated with a highly degraded condition of the individual. In fact, a large number of evaluated trees showed a moderate or high failure risk related to root, collar and trunk degradation, mainly due to $K$. deusta, in a few cases associated with other wood and root rot agents. Because of the natural condition of almost all the sites, the majority of veteran trees are not threatened by bad management, though two of the worst trees (Cà vecia-4 and Villa Pia-15) were heavy pruned about 10-15 years ago. Therefore, the physiological processes of aging can be considered as the main driver of their health condition evolution; as suggested by Lonsdale (2013) veteran trees are a living lab to understand the processes in which wood degrading fungi play a fundamental role. But the presence of structural defects related to these processes also means that most of these trees are at risk of failure and constitute a problem for the community in the absence of adequate management or information about the possible danger.

To confirm this, four of the surveyed trees fell during the last four years (20162020): three of these had $K$. deusta and high risk evaluation and one without evidence of $K$. deusta and low risk (Tab. S1 in Supplementary material). Probably most of these breakdowns happened during wind or snow storms but in at least three cases it is conceivable that the parasite weakened the root apparatus. The case study of the tree that fell during the survey is really interesting; this beech, which had had a severe pruning of two main branches about 15 years ago, showed a quite complete colonization of collar and trunk by K. deusta, with evidence also of Armillaria spp. at the moment of the survey, resulting in a high failure risk class. It fell suddenly, exactly two weeks after evaluation in the absence of a storm but at the restarting of the vegetative season when new foliage and water contents increased the crown weight. In the last years, this kind of failure at the beginning of the vegetative season was also observed on other veteran trees affected by $K$. deusta in Trentino (Maresi, pers. comm.), confirming the potential danger due to the pathogen presence also in absence of extreme weather events.

Regarding this aspect, the evident difficulties in recovering signs of the presence of the fungus in the VTA should be remembered and, mainly, the extent of its wood tissues colonization and degradation. Evidence of fruiting bodies is sometimes the only way to identify the pathogen, but it indicates an advanced colonization, while instrumental analysis sometimes proved less effective because of the particular degradation of wood tissues (Deflorio et al. 2008). On this subject, biomolecular analysis for an early detection of the fungus proved efficient in the urban contexts (Guglielmo et al. 2010, Giordano et al. 2015) and it could also be adopted for veteran trees in more natural contexts. Anyway, the detection of the fungus only attests to its presence but the evolution and timing of wood colonization remain very difficult to forecast because of the multiple factors involved, such as plant status and environmental conditions.

$K$. deusta was present around the veteran trees in the investigated beech wood: the fungus was found in most of the areas (33 out of 40) as a quite common presence on both stumps and living trees. This observation confirms those of other authors who reported $K$. deusta as a common component of the mycoflora of beech woods, especially in old growth stands both in Italy (Granito et al. 2015, Persiani et al. 2016) and Europe (Baldrian et al. 2016, Heine et al. 2019). These recent records do not consider the fungus mainly as saprotroph or debris colonizer, but its damaging potential as a pathogen had already been recognized in the past (Wilkins 1934). Moreover, the fungus was found to be damaging beech trees at a high rate both in Czechoslovakian and Yugoslavian woodlands (Prljnčevič 1982), while more recently, its pathogenic role in urban tree management was enhanced (Guglielmo et al. 2010, Giordano et al. 2015). Thus, K. deusta can act as cause of damage on old trees, as observed in our survey, but it could also be considered as a more effective agent for the possible evolution of old growth beech stands. Interestingly, the easily recognized $K$. deusta spores were considered in paleopalynology a valid proxy to understand the evolution of forest cover; it should be remembered that $\mathrm{K}$. deusta is common on $\mathrm{Fa}$ gus, but can also affect other genera including Acer, Aesculus, Alnus, Betula, Carpinus, Castanea, Fraxinus, Populus, Quercus, Salix, Taxus, Tilia and Ulmus (Van Geel et al. 2013). The ascospores recovery in lake or moorland pollen deposits was correlated mainly to an increase or decrease in deciduous species in the surroundings woodland, but in some cases spore peaks were also associated to some particular extreme weather conditions such as rainstorms affecting beech woods (Van Geel et al. 2013) or to a drastic decline as reported for Ulmus sp. in northern Europe (Innes et al. 2006).

In this context, it is still difficult to assess a possible role of climate change in the development of infections and spread of the fungus. Anyway, the constant increase of temperature also in the Alpine region could suggest a longer favorable period for mycelium growth and also for germination of its spores (Wilkins 1934). In fact, data obtained in this study confirmed a positive growth range of the fungal isolates between 10-30 degrees with an optimum at $25{ }^{\circ} \mathrm{C}$, as reported in previous studies both in Europe and Italy (Wilkins 1934, Capretti et al. 2003). In addition, palaeoecological reconstructions of forest dynamics of Ulmus in the United Kingdom and Tilia in Poland (Innes et al. 2006, Latalowa et al. 2013), suggested a likely increase in the growth rate and success of $K$. deusta infection due to the rise of few degrees in the average annual temperature, and hypothesized an increased risk of $K$. deusta outbreaks in a warming climate condition.

The possible role of the multiple wounds on collar and roots of the assessed veteran trees could also be considered in the epidemiology of the parasite, because they are preferential ways of colonization of the host (Guglielmo et al. 2012). A stress condition due to meteorological events could also affect the callusing and compartmentalization ability of the trees.

$K$. deusta, considered up to now a minor parasite if not a saprotroph, could instead play a more incisive role both in the decline of old beech trees and in the natural evolution and aging process of woods. This possible role deserves more investigations, especially regarding the relationship with climate change. Moreover, the risk evaluation highlighted how the fungus presence along with other kinds of damage could affect the survival and safety of these veteran trees. On this subject, the obtained results emphasised the need for an appropriate management of the veteran trees, as already suggested by Lonsdale (2013) and Farina et al. (2019), aimed to preserve them as long as possible and assure the reduction of any risk for their fruition and enhancement.

\section{Acknowledgements}

The authors thank Stefano Corradini for 
his valuable technical support.

\section{References}

Baldrian P, Zrustová P, Tláskal V, Davidová A, Merhautová V, Vrška T (2016). Fungi associated with decomposing deadwood in a natural beech-dominated forest. Fungal Ecology 23: 109-122. - doi: 10.1016/j.funeco.2016.07.001 Capretti P, Menguzzato G, Maresi G, Luchi N, Moriondo F (2003). Fenomeni di deperimento e moria in popolamenti artificiali misti di latifoglie e conifere [Decline and death phenomena in mixed artificial stands of conifers and deciduos trees]. Annali dell'Accademia Italiana di Scienze Forestali 52: 3-30. [in Italian]

Deflorio G, Fink S, Schwarze F (2008). Detection of incipient decay in tree stems with sonic tomography after wounding and fungal inoculation. Wood Science Technology 42: 117-132. doi: 10.1007/s00226-007-0159-0

Farina A, Camoriano L, Cuaz G, Maroè A (2019). Linee guida per gli interventi di cura e salvaguardia degli alberi monumentali [Guidelines for monumental trees management]. Alberi Monumentali d'Italia, Direzione Generale Delle Foreste-Regioni, Ministero delle politiche agricole alimentari e forestali - MiPAAF, Rome, Italy, pp. 57. - [in Italian] [online] URL: http:// www.politicheagricole.it/flex/cm/pages/ServeB LOB.php/L/IT/IDPagina/13732

Giordano L, Sillo F, Guglielmo F, Gonthier P (2015). Comparing visual inspection of trees and molecular analysis of internal wood tissues for the diagnosis of wood decay fungi. Forestry 88 (4): 465-470. - doi: 10.1093/forestry/cpv015 Granito VM, Lunghini D, Maggi O, Persiani AM (2015). Wood-inhabiting fungi in southern Italy forest stands: morphogroups, vegetation types and decay classes. Mycologia 107 (6): 10741088. - doi: 10.3852/13-400

Guglielmo F, Gonthier P, Garbelotto M, Nicolotti $G$ (2010). Optimization of sampling procedures for DNA-based diagnosis of wood decay fungi in standing trees. Letters in Applied Microbiology 51: 90-97. - doi: 10.1111/j.1472-765X.2010.028 60.x

Guglielmo F, Michelotti S, Nicolotti G, Gonthier P (2012). Population structure analysis provides insights into the infection biology and invasion strategies of Kretzschmaria deusta in trees. Fungal Ecology 5 (6): 714-725. - doi: 10.1016/j.fun eco.2012.06.001

Hall SJG, Bunce RGH (2011). Mature trees as keystone structures in Holarctic ecosystems - a quantitative species comparison in a northern English park. Plant Ecology and Diversity 4: 243250. - doi: 10.1080/17550874.2011.586735

Heine P, Hausen J, Ottermanns R, Schäffer A, Roß-Nickoll M (2019). Forest conversion from Norway spruce to European beech increases species richness and functional structure of aboveground macrofungal communities. Forest Ecology and Management 432: 522-533. doi: 10.1016/j.foreco.2018.09.012
Herrera CS, Hirooka Y, Chaverri P (2016). Pseudocospeciation of the mycoparasite Cosmospora with their associated fungal hosts. Ecology and Evolution 6: 1504-1514. - doi: 10.1002/ece3.1967 Innes J, Blackford J, Chambers F (2006). Kretzschmaria deusta and the northwest European Mid-Holocene Ulmus decline at Moel Y Gerddi, North Wales, United Kingdom. Palynology 30: 121-132. - doi: 10.1080/01916122.2006.9989622

Latalowa M, Pedziszewska A, Maciejewska E, Swieta J (2013). Tilia forest dynamics, Kretzschmaria deusta attack, and mire hydrology as palaeoecological proxies for mid-Holocene climate reconstruction in the Kashubian Lake District (N Poland). The Holocene 23: (5) 667-677. doi: 10.1177/0959683612467484

Lindenmayer DB, Laurance WF, Franklin JF (2012). Global decline in large old trees. Science 338: 1305-1306. - doi: 10.1126/science.1231070 Lonsdale D (2013). Ancient and other veteran trees: further guidance on management. The Tree Council, London, UK, pp. 212.

Luley C (2017). Kretzschmaria deusta, a common decay fungus you may not recognize. Tree Care Industry 28: 24-29.

Manning A, Fischer J, Lindenmayer D (2006). Scattered trees are keystone structures - implications for conservation. Biological Conservation 132: 311-321. - doi: 10.1016/j.biocon.2006.04. 023

Matheny NP, Clark JR (1994). Evaluation of hazard trees in urban areas ( $2^{\text {nd }}$ edn). International Society of Arboriculture - ISA, Champaign, IL, USA, pp. 85 .

Müller E, Stierlin HR (1990). Sanasilva - Le chiome degli alberi [Sanasilva - The tree canopy]. Swiss Institute for Forest, Snow and Landscape Research, Birmensdorf, Switzerland, pp. 129. [in Italian]

Orlowski G, Nowak L (2007). The importance of marginal habitats for the conservation of old trees in agricultural landscapes. Landscape and Urban Planning 79: 77-83. - doi: 10.1016/j.land urbplan.2006.03.005

Persiani AM, Lombardi F, Lunghini D, Granito VM, Tognetti R, Maggi O, Pioli S, Marchetti M (2016). Stand structure and deadwood amount influences saproxylic fungal biodiversity in Mediterranean mountain unmanaged forests. iForest 9: 115-124. - doi: 10.3832/ifor1304-008

Pezzi G, Gambini S, Buldrini F, Ferretti F, Muzzi E, Maresi G, Nascimbene J (2020). Contrasting patterns of tree features, lichen, and plant diversity in managed and abandoned old-growth chestnut orchards of the northern Apennines (Italy). Forest Ecology and Management 470471 (784): 118207. - doi: 10.1016/j.foreco.2020.11 8207

Prljnčevič MB (1982). Economic significance of the infection of beech forest by Hypoxylon deustum (Hoffm. et Fr.). European Journal of Forest Pathology 12: 7-10. - doi: 10.1111/j.14390329.1982.tb01366.x

Read H (2000). Veteran trees. A guide to good management. English Nature, Peterborough, UK, pp. 1-167.

Rogers JD, Ju YM (1998). The genus Kretzschmaria. Mycotaxon 68: 345-393. [online] URL: http://www.cabdirect.org/cabdirect/abstract/19 981008667

Smiley ET, Matheny N, Lilly S (2017). Best management practices: tree risk assessment $\left(2^{\text {nd }}\right.$ edn). International Society of Arboriculture ISA, Champaign, IL, USA, pp. 81. [online] URL: http://www.cabdirect.org/cabdirect/abstract/2 0183082467

Tudoroiu M, Eccel E, Gioli B, Gianelle D, Schume H, Genesio L, Miglietta F (2016). Negative elevation-dependent warming trend in the Eastern Alps. Environmental Research Letters 11 (4): 044021. - doi: 10.1088/1748-9326/11/4/044021

Van Geel B, Engels S, Martin-Puertas C, Brauer A (2013). Ascospores of the parasitic fungus Kretzschmaria deusta as rainstorm indicators during a late Holocene beech-forest phase around lake Meerfelder Maar, Germany. Journal of Paleolimnology 50: 33-40. - doi: 10.1007/s10933013-9701-2

White TJ, Bruns T, Lee S, Taylor JW (1990). Amplification and direct sequencing of fungal ribosomal RNA genes for phylogenetics. In: “PCR Protocols: A Guide to Methods and Applications" (Innis MA, Gelfand DH, Sninsky JJ, White TJ eds). Academic Press, New York, USA, pp. 315-322.

Wilkins WH (1934). Studies in the genus Ustulina with special reference to parasitism. Introduction, survey of previous literature and host index. Transactions of the British Mycological Society 18: 320-346. - doi: 10.1016/Sooo7-1536(34) 80017-4

Zapponi L, Mazza G, Farina A, Fedrigoli L, Mazzocchi F, Roversi PF, Sabbatini Peverieri G, Mason $F$ (2017). The role of monumental trees for the preservation of saproxylic biodiversity: rethinking their management in cultural landscapes. In: "Monitoring of Saproxylic Beetles and Other Insects Protected in the European Union" (Campanaro A, Hardersen S, Sabbatini Peverieri G, Carpaneto MG eds). Nature Conservation 19: 231-243. - doi: 10.3897/natureconserv ation.19.12464

\section{Supplementary Material}

Fig. S1 - Veteran beeches are keystones of the Trentino landscape.

Fig. S2 - Cosmospora berkeleyana perithecia growing directly above the stromata surface of $K$. deusta, and structure of asci and ascospore.

Tab. S1 - Surveyed veteran beech sites with $K$. deusta presence and risk status.

Link: Cordin_3830@supploo1.pdf 